\title{
Households without Houses: Mobility and Moorings on the Eurasian Steppe
}

\author{
JOSHUA WRIGHT, Department of Anthropology, Oberlin College, Oberlin, \\ OH 44074,USA.Email: jwright@oberlin.edu
}

\begin{abstract}
Mobility is often cited as the essence of life in the Eurasian steppe, and with it mobile dwellings and households. Steppe nomads offer ethnographically potent visions of inhabited space into which archaeological landscapes fit comfortably. Challenges include the discovery of early household sites, the characterization of households that lack structures, and how to examine the dynamics of mobile pastoralist households without being drawn into an agglomerative model that builds toward optimal practices. This paper will marshal the archaeological evidence for domestic spaces in mobile steppe households. A flexible and extensible model of household spaces will be offered that links activities and resources into a network of contextual relationships at the household scale. This provides a model for analogical use of ethnographic data, frameworks into which the archaeological fragments of mobile households can be fitted, and above all a means of comparative characterization between periods of inhabitation in the world's steppes.
\end{abstract}

Key words: campsites, corrals, ethnoarchaeology, Khitan, mobility, Mongolia, nomads, pastoralists, small-scale social networks

As a traveler unsure of your way in the Mongolian steppe, a group of white domed structures set against the skyline is a welcome sight. Approaching closer, you can see a cart or battered jeep at the edges of the row of gers (Figure 1). Moving up the slope toward the camp you cross the penumbra of worn ground and trampled dung around a large herd's bedding areas. No animals or herders are to be seen, but both people and animals have been living here for weeks and might be moving soon. As you sweep into the camp and stop at a place within easy shouting distance of the dwellings, dogs lift their heads and consider if they will bark or just amble out to investigate the new arrivals. Everyone pauses for a moment as the dust settles and the dogs decide their next move. Then a woman emerges from the ger's door, you step down from your vehicle and exchange greetings. Both visitor and host walk into the ger, stepping over the threshold, and as she turns to the right inside the door, you turn left to the visitors' seating area and, greeting other members of the family, sit down and ask, "Where is the road we're looking for?"

Published online: March 30, 2016

Journal of Anthropological Research (Summer 2016). (C2016 by The University of New Mexico. All rights reserved. 0091-7710/2016/7202-0002\$10.00 


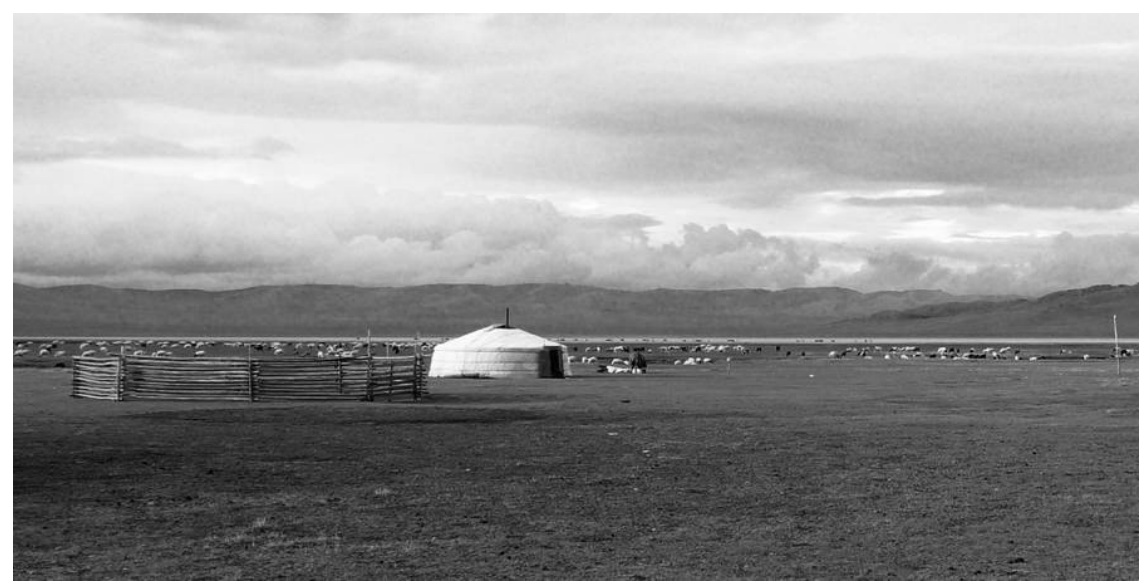

Figure 1. View of a campsite in Omngovi Aimag, Mongolia.

\section{HOUSEHOLDS WITHOUT HOUSES}

The spatial archaeology of households is immediately intuitive. Look at a site plan and your eye jumps with ease from one appropriately configured household unit to the next as your mind populates those domestic spaces and the public territory around them. The mutual relationship between a household's physical fabric and its household culture has long been understood. It is this interrelationship between distinctive and small-scale physical structures and particular behavior, along with easily approachable domestic objects, that gives household archaeology its intimacy and immediacy (Glowacki and Vogeikoff-Brogan 2011; Hendon 2008; Wilk and Rathje 1982). Though spaces, domestic objects, and activity areas may provide entrances into household archaeology, the house itself is the typical starting point (Ames et al. 1992; Glowacki and Vogeikoff-Brogan 2011). This need not always be the case. The fundamental assertion of this paper is that households without enduring dwelling structures are much like any other households- not in the fabric of their construction or their settings, but in the ways that they embody culture, give meaning to everyday activities and encounters, and provide central places for a range of household activities. Instead of beginning with four walls, this study is built from the premise that it is household actions that create inhabited spaces and dwelling places (Ingold 2000; Lefebvre 1991) as much as an enduring construction might do.

This study takes place in the Eurasian Steppe Belt, a broad region of grassland that stretches from Hungary to China with an analogous territory spanning North America. In Eurasia this grassland has supported subsistence based on the regular movement of herds and the use of mobile dwellings and wheeled vehicles for at least 4,000 years (Anthony 2007; Hanks 2010). The analogous ecosystem in North America also saw the rise of complex societies in which mobility was a central element (Hämäläinen 2003). 
Do not begin with the sense that there are no house structures in the archaeological record of Eurasia. Cabins, pithouses, villages, palaces, and towns have been found and excavated there (Becker and Fassbinder 1999; Danilov 2011; Davydova 1968, 1995; Gorynova 1983; Kato and Shiraishi 2005; Kradin and Ivliev 2008; Larichev and Pforr 1962; Perlee 1962; Ramseyer and Turbat 2007), but it is the long history of mobile pastoralism for which the region is justly famous. Built elements are parts of mobile pastoralist households and are, in some cases, detectable in the archaeological record in Mongolia and other regions of Eurasia (Anthony and Brown 2007; Chang and Koster 1986; Cribb 1991a; Hammer 2014; Humphrey 1974; Piggott 1944; Spengler et al. 2013; Umekazu et al. 2010; see also Potts 2014). The great majority of sites in this region from all periods, however, do not exhibit structural remains. These sites are for the most part artifact scatters that are interpreted as the scant material evidence of ancient dwelling spaces. Because these sites make up the majority of the material recorded by intensive archaeological surveys on the steppe (Amartuvshin and Honeychurch 2010; Honeychurch and Chunag 2007; Honeychurch et al. 2007; Houle and Erdenebaatar 2009; Williams 2008; Wright et al. 2007, 2009, n.d.), they offer a dataset that is potentially rich in ethnoarchaeological comparisons and evidence for ancient social relations. In this paper I present a spatial model for the study of household archaeology that is flexible, extensible, focused on household activity, and suited for mobile contexts.

The study of mobile pastoralist households owes much to the study of house structures, but more to the study of hunter-gatherer campsites. That work has highlighted the purposeful—if minimal—infrastructural investment (Binford 1978; Hodgetts 2007), the economic aspects of spatial organization (Binford 1980; Mithen 2000; Weber and Bettinger 2010; Wood and Marlow 2014), the centrality of kinship interactions (Fisher and Strickland 1989; Whitelaw 1983), networks (Hill et al. 2011), and mobility (Kelley 1992; Weber and Bettinger 2010). The campsites, and households, of mobile pastoralists have been the subject of much less archaeological and ethnoarchaeological investigation than those of hunter-gatherers. These topics have common ground with the study that follows in the relations of local landscape shape to site arrangement, particularly for the management of visibility and shelter from weather and sun (Head and Fullagar 1997; Iakovleva et al. 2012; Mitchell et al. 2011), and place-making and long-term repeated use of distinctive locales (Head and Fullagar 1997; Luby et al. 2006). An important caveat here is that studies of hunter-gatherer campsites typically look at larger economic and social units than single households. This paper will concentrate on single herding groups of mobile pastoralists operating as a single economic and social unit.

The route that this paper will take begins first with Mongolian ethnography framed by the anthropology of mobility, moving then to ethnoarchaeology and finishing with archaeological data. The data are drawn from archaeological surveys carried out in northern Mongolia and the Gobi Desert (Figure 2). The ethnographic data used here represent typical configurations of herding households primarily from the 


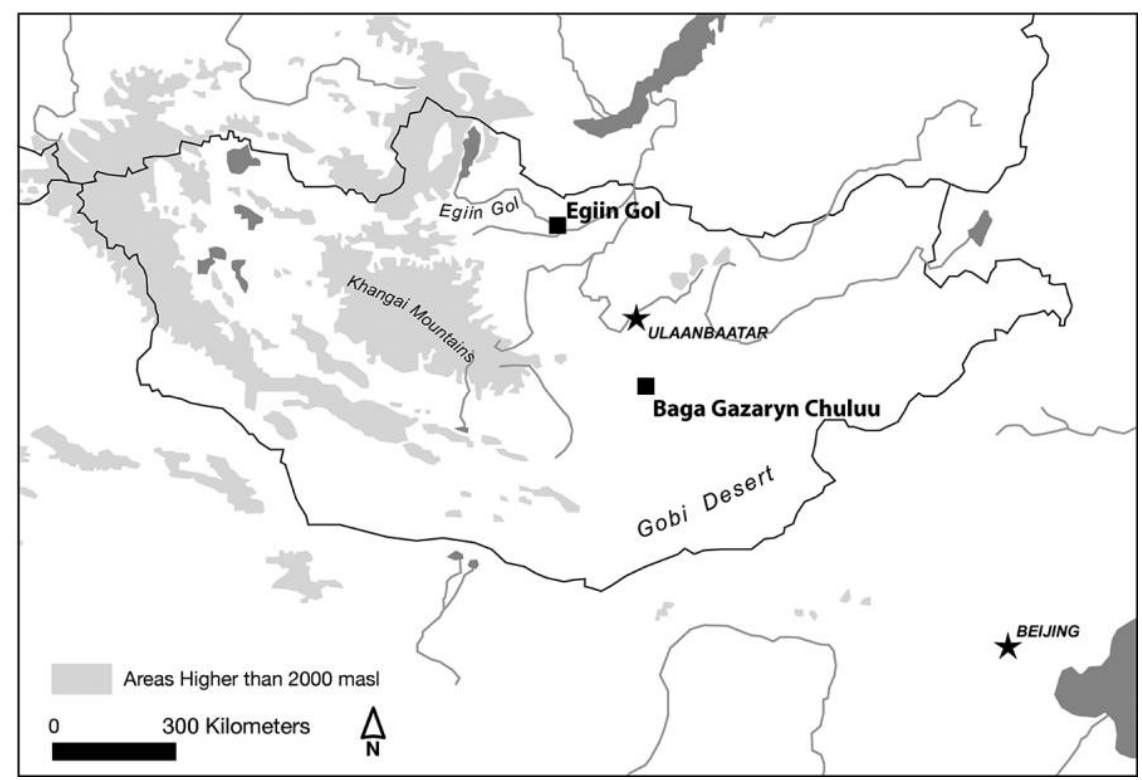

Figure 2. Map of Mongolia showing the study areas of Baga Gazaryn Chuluu and the lower Egiin Gol valley.

Middle Gobi and Khangai regions of Mongolia (Mearns 1993; Simukov 2007). The economy and material culture in these study areas are seen throughout the eastern half of the Eurasian steppe belt. The primary focus of the analysis is to develop methods of discovering household structure in the surface archaeological record and relating those to larger-scale landscape studies of the steppe.

\section{THE ETHNOGRAPHY OF MONGOLIAN HOUSEHOLDS}

Like mountains, ideal old men are still; like mountains, ideal old men are the epitomes of solidity; like mountains, ideal old men constitute focal points in whose vicinity human as well as nonhuman life-forms are supposed to gather (Pedersen 2006:99-100).

Among modern Mongolian pastoralists the basic household unit is an economic one. The herding group or khot ail is made up of one to five nuclear family groups and associates who work together to manage their various animals. This unit typically lives and moves together, but in some seasons may split apart. The khot ail is managed by an active senior member of either gender who makes decisions about labor, movement, and animals' lives (Erdenebaatar 1996; Fernandez-Gimenez 2006; Jagchid and Hyer 1979; Mearns 1993; Simukov 2007; Vainshtein 1980). The close relationship between the success of economic adaptations and household structure 
and work scheduling (Wilk and Rathje 1982) is also seen in other examples of Eurasian nomadic pastoralist labor organization and settlement structure (Beck 1991; Ekvall 1968). The nature of living and working spaces in these short-term settlements, the relationships among the people who populate them, and the shared mobility of a herding group have led to the use of the term "household" to describe a herding group and their physical situation, a campsite.

The campsite is inhabited most of the time by women, children, and the elderly. It is also where the most complex interactions between people and other species take place (Fijn 2011). Herds, friends, and strangers draw together here, animals are milked here, the milk is processed and consumed, and decisions are made that affect the lives of animals. Movements within a campsite are defined by tasks, waste disposal, and social divisions of spaces, but above all by gender, age, and species. The relations of people and animals structure campsites, particularly the spaces needed for herders to manage animals and their secondary products. Human social spaces and those used for production are wrapped within the multi-species spaces of corrals and animal activity areas. The social order of a pastoralist household includes both humans and animals.

The "ideal old men" of the quote that opened this section do not appear to fit this model of pastoral nomads. They do not move as nomads should; they may not manage large herds or divide the tasks of the household as rigorously as they might otherwise do. Their existence is the factor that shifts the study of nomadic pastoralist households away from solely economic-based modeling and toward an approach that treats households as fundamental elements of social order (Pedersen 2006; see also Cribb 1991b). We see in the "ideal old men" a balance between fixity and mobility and the importance of multi-actor systems that orbit around central places.

In some cases those central places could be uninhabited locales, such as the mountains mentioned in the quote, or, in the past, monumental sites (JacobsonTepfer et al. 2010; Wright 2007, 2014), but more frequently they are the residences of old people and active campsites. These focal points can provide measures against which the mobility of others is measured.

The iconic image of a Eurasian nomad's camp is the mobile dwelling, known as a ger in Mongolian or yurt in other Central Asian languages. From the outside they are almost always the same size, the same color, and indicative of a similar set of relationships between people, animals, and landscape. It is the regularly structured interiors of these dwellings (Humphrey 1974; see also Yates 1989) that make visible the relationships of kin and outsiders as well as relationships with the material things that are necessary for daily work or exceptional events around the household. Outside this ephemeral interior space, mobile campsites themselves are ordered spaces. The process of disassembling and assembling any camp follows a sequence of movements performed in one direction or the other. The dwellings provide a field not only for household actions, but for a whole array of areas and activities that are recreated in similar relation to one another every time they are assembled. Pedersen 
(2009) has described this as a "packable sense of place" which, like the constant shape and elements of a campsite, manages the perceptions and possibilities of limitless horizons of distance and movement.

Thus far I have been presenting campsites as areas with defined boundaries as you might find in the case of a dwelling structure. But in addition to herding, many other actions that are regularly associated with campsite activities cross the boundaries in both haphazard and structured ways. These are primarily activities such as bringing water and fuel (wood or dung) to the household, but also foraging in the vicinity of campsites (Rautio et al. 2014) and child's play. Boundaries are never defined by structures; typically, structures (corrals, portable cabins or storage shelters) are near the center of camps. The edges of a campsite include areas for animals to stand, the range of the camp's dogs, latrines, and disposal zones.

This unpacking of a sense of place (Pedersen 2009) does not occur just anywhere. A set of factors refracts a landscape into an array of different spaces, each with qualities favored by nomadic pastoralists in different seasons and with different practical needs. Around campsites, these factors include the topography that provides shelter and answers the needs of animals; the management of wind flows around animals and dwellings; the morning sun; access to transportable water; space to maneuver and arrange herds close to home, and more (Joly et al. 2013; Kakinuma et al. 2008; Simukov 2007; Umekazu et al. 2010; Vainshtein, 1980; Zemmrich et al. 2010). Combinations of all these local landscape elements create a multiplicity of useful spaces. With so many possibilities, ideal ground is rare and compromises in campsite setting are frequent.

The model presented here is one in which the physical structure of a household has a fixed form, but in contrast to that fixity of form the households are mobile and do not have fixed locales. Familiar relationships can be found in any campsite, but the paths and views beyond the boundary of the camp will change with every move. This is also a gravitational model of a household in which everything is in motion and all parts are attracted toward each other. A herding group moves and camps together while bringing their sheep to good grazing places. The sheep stay together in a herd, while herders return with their horses to campsites that favor particular topographic locales or proximity to places or particular people. Campsites have familiar arrangements of activity areas-milk is processed at stoves or in kitchen areas, horses are tied to the hitching line, and equipment is stored in particular places. Overall, the household is both a collection of regularly arranged activities and objects and a center point for a large array of movements divided and structured by age, gender, and species.

\section{FIXITY AND MOBILITY}

All households are networks of interactions, but this is particularly visible in a mobile setting where so many other activities fit easily into a network model. Households here are made up of interactions of a wide range of related actors-humans, 
animals, environmental features, and objects (Latour 2005; Law 2009; see also Urry 2000)_all of which are, in a sense, capable of action because they do things to sustain the household and affect the arrangements of other elements around them (de Laet and Mol 2000). No element of the household (dwellings, people, sheep, weather, horses, buckets, etc.) can fail or the whole system may collapse. Failure, however, is a deep and variable zone. For example, a devastating early spring storm might result in the death of many animals (Jacobs 2010), and though this failure will challenge the herders' abilities, it will not destroy the herders' household. They will act to save the core of their herds by moving, foddering, using stronger animals to break ice crusts, and so on (Murphy 2012; Xie and Li 2008).

Eurasian mobile pastoralist households and herding practices are fluid systems (Aldred 2013; de Laet and Mol 2000; see also Büscher and Urry 2009; Urry 2000). This fluidity can be seen in the several interlinked layers that make up mobile households. One is the network of choices made by nomads in their daily lives as pastoralists (Aldred 2013; Humphrey-Waddington 1974; Lattimore 1979). Second is the way in which mobile households are continuously disassembled and recreated following the same basic plan but also responding to their specific setting (cf. de Laet and Mol 2000). At a smaller scale we see that specific pieces of a camp (ger poles or bowls for settling milk, or camels) will be switched out for essentially identical elements as the household continues, a mechanism in constant motion.

In contrast to this constant motion are fixed points in a mobile landscape, and not just ideal old men or mountains, that anchor patterns of movement (Hammer 2014) within the life experience of individual nomads. For pastoralists, the flows of the interrelated necessities of people and animals come together in a range of places (Aldred 2013; Ingold 1993). These lasting landscape anchors (Hammer 2014) are things such as winter corrals, surface water, wells, cemeteries (Ho 2006), or enduring stone-built monuments (Bender et al. 2007; Wright 2012) that draw people back to places and keep them close. In contrast to the long-term fixity of these examples, ${ }^{1}$ for the weeks between camp moves (Mearns 1993; Simukov 2007), campsites themselves provide moorings for the movements of the household.

There is a relationship of fixed and moving elements in any household or house, but in the case of Eurasian mobile pastoralists the fixed elements are stripped down to a bare minimum and movement is a pervasive quality. Fixity and mobility are relative qualities, and relative movement is a key constitutive relationship of a social landscape. A nomadic household moves, but when it is stationary the household itself becomes a fixed point around which mobile elements move. Moorings such as these are an essential element of mobility (Adey 2006), marking moments of rest in patterns of movement. Herders and animals move about on the surrounding range; children and cheese-makers move within the space defined by mobile dwellings, milking lines, and disposal areas.

Seen at different time scales and from different standpoints, mobile households are both stable and unstable. In the short term they are solid anchors for a herding 
pattern and a social network. Seasonally they are always in motion, moving from place to place in pursuit of graze and water for their herds. A stable yearly pattern will bring a household back to the same small valley or river terrace again and again. And over the life span of an individual they may move large distances to new surroundings. The ultimate stability comes, however, from the repeated and nearly identical assembly of a campsite each time the household moves. The world around the household changes quickly, but the household itself changes slowly.

\section{APPROACHES TO NOMADIC HOUSEHOLDS}

The archaeology of nomadic households could be approached through many avenues, ranging from geomorphology to molecular archaeology. The topography of a site is one starting point. By considering the locations of artifact scatters and of the active and inactive modern campsites we can see that shelter from wind and weather is a key factor in site location and configuration. Generally, slightly sloped ground is favored, and the flattest ground is reserved for sheep bedding and lambing areas in the spring. Disposal areas might be pits, over the edge of nearby slopes, or into narrow slots between rock outcrops. All these factors may be detectable as microtopographic features. The most enduring elements of most campsites are the stones that have been moved or modified. Though formal structures are rare, the foundations or remains of winter corrals are sometimes found. We also see traces of terraced platforms built to level dwelling floors, cairns piled up as ground is made more comfortable for animals, stone gathered to support posts, and blessings or marks of allegiance pecked into larger stones around campsites (see de Haas 2012; Hammer 2014; Wilkinson 2003 for examples in western Eurasia).

Functional interpretations of ceramics collected over small areas within sites or immediately around them might be a way to isolate areas where particular activities took place. However, it is more likely that the spatial distribution of ceramics at this scale can provide information mostly on disposal areas, high-traffic areas, and the general type of activities that might have taken place at a site as a whole, rather than at a specific location within it. Faunal studies can shed light on foddering and penning practices at or around individual campsites or within individual herds (Makarewicz 2011, 2014; Makarewicz and Tuross 2006). Finally, the study of soil and soil chemistry has proved a fruitful approach to small sites with minimal surface expression (Shahack-Gross et al. 2004; see also Cavanagh et al. 2005).

This paper presents nomadic pastoralist households as a set of nodes, or actors, in a network of interrelationships. Archaeological and ethnographic examples of campsite households provide starting points to allow each site to be examined as a small network of activity zones with connections to close and far away locales and activities. Ethnographic records are rich with variation, defined zones of activity, and easily identifiable activities. Archaeological sites have far fewer identifiable elements, and most of those could well be the result of repeated uses at different times. 
The data used in this study come primarily from Baga Gazaryn Chuluu (BGC), a $120 \mathrm{~km}^{2}$ range of hills in Dornogovi Aimag (Figure 2). This region of Mongolia has been fully surveyed (Amartuvshin and Honeychurch 2010; Wright et al. 2007) using intensive site-focused methods designed to record small features and ephemeral sites as well as macro features and large complexes of monuments (Burger et al. 2004; Fish and Kowalewski 1990; Kowalewski 2008; Plog et al. 1978; Sundstrom 1993; Wright 2010). The site definition threshold was low-three proximate artifacts or one other feature along a $120 \mathrm{~m}$ survey line would invoke a more detailed examination of the area, and five artifacts in $100 \mathrm{~m}^{2}$ would be defined as a site for further study. In practice, most sites were well over this threshold. In addition, the modern domestic and wild sheep populations and herding practices at BGC were studied (Makarewicz 2011; Makarewicz and Tuross 2006). Survey teams recorded the locations of many modern and recent campsites. BGC has been well documented in 1970s aerial photographs, and modern satellite imagery showing the general forms of many campsites is publicly available. Additional details are drawn from campsite sketch maps made in the lower Egiin Gol valley, in Bulgan Aimag of northern Mongolia (Honeychurch 2014; Torbat et al. 2003; Wright et al. 2009, n.d.). The ethnographic data and campsite maps provide many details of modern campsite activities (see also Umekazu et al. 2010). Imagery and archaeological recording are less rich, although some aspects of the two datasets can be examined. Foremost are the relationships of natural shelter (rock outcroppings), constructed shelter, substantially altered ground (primarily animal travel routes, but also erosion and downslope flows from corrals), the location of gers, and the extents of campsites.

\section{Campsites in the Lower Egiin Gol}

Figure 3 shows two detailed plans of nomadic pastoralist campsites in the lower Egiin Gol shortly after their inhabitants moved on. Though these sites are complex and appear different at first glance, they contain common elements and patterns. Foremost among these are working pairs of locations within the campsites, the relations of animal standing or bedding areas to dung piles, and of dwellings to kitchens to wood piles, and so on. From an archaeological standpoint it is notable that in these sets, only one of the elements might leave a detectable archaeological trace on the ground surface.

Modern activities around such campsites can also help to clarify the material residues left by nomadic households. Household activities require particular tools and types of spaces, and they leave particular remains. Looking at the campsites as small networks in which interlinked activities take place at different nodes around the campsite further differentiates space (Figure 4). For example, a bowl of aaruul (dried cheese) in a ger's eating area (A in Figure 4) was stored in a box or bag on the eastern side of the ger's doorway (Humphrey 1974) and dried on the ger's roof or the kitchen rack (B). The initial cheese from which the aaruul was made was itself produced with a weight and cheeseboard situated near the kitchen from milk 

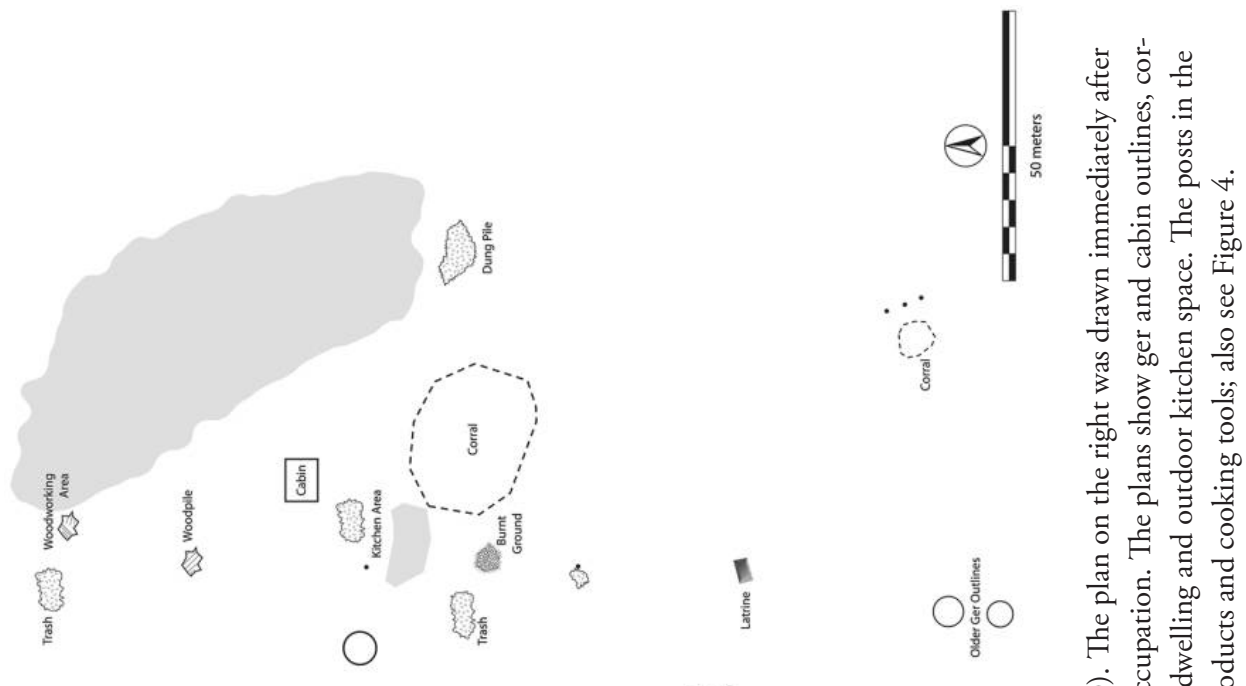

0

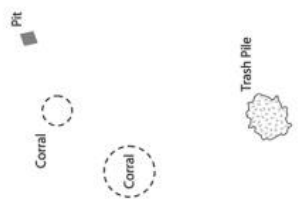

(3)
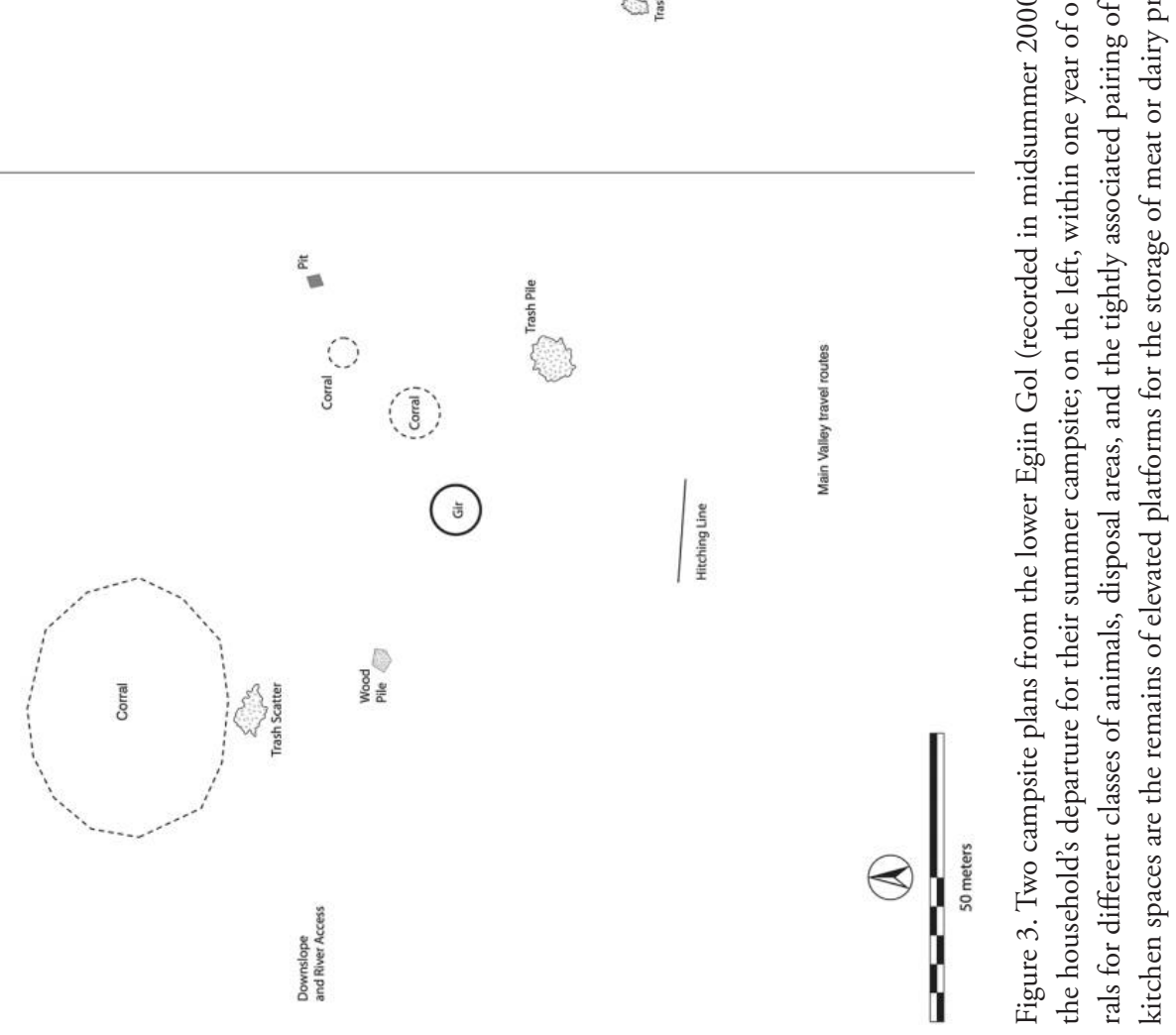

This content downloaded from 139.133.148.027 on May 18, 2016 03:40:08 AM 




Figure 4. A schematic plan of a campsite depicting activity areas used for the making of aaruul (inset). Types of activity areas are shown as circles designated by letters; the dwelling is indicated by a heavy circle. Poles define the kitchen and the hitching line. Animal corrals as well as wood and trash piles are also illustrated. The gray area shows disturbed ground, sheetmidden, and dung fields where animals might stand while being herded close to camp (D) or being milked (C). Arrows schematically illustrate movements between locations, with heavier arrows showing more regular paths. Aaruul image by Mizu Basyo, used with permission.

collected at the milking line at the edge of an animal standing area or a corral (C). The animals spent most of their day eating and resting on the range, returning from their pastures along a regular path into and out of the campsite (D), where they were organized and divided in the open ground near the campsite (E). The herders at the campsite and their various tools enter this sequence in different ways and as parts of their own active routines around the household. Gender is central to these moving elements of the ethnographically observed household network. Women may be most active around $\mathrm{A}, \mathrm{B}$, and $\mathrm{C}$, whereas men will be most active at D and $\mathrm{E}$, and again in $\mathrm{A}$, with a handoff of sorts between genders occurring between $\mathrm{C}$ and D. The animal herd is split by sex and age at $\mathrm{E}$, and only milk-producing females and young animals participate in the story of the aaruul from that point. Women 
and female animals are active in the most spaces within a campsite; this is a mirror image of the gendered landscape of the steppe itself, where lone men and mixed animal groups are most active.

The same process of tracing networks can be repeated for different production sequences, the arrival of strangers, the butchery of animals, and so on. The nodes of the campsite household are connected through those repeated activities and movements between them. What emerges from this examination is the key triangle of ger, kitchen, and hitching line. The dwelling itself is a central place where many things happen, but few people or objects approach it without first passing through the kitchen (B) or the hitching line (F). In terms of network terminology, those places become what are called high-degree vertices (ones with many connections) or "brokers" in that they are key to the passage of activities around the network in general (Newman 2010).

\section{Ethnographic Campsites at Baga Gazaryn Chuluu}

Stepping back from the detailed plans of Figure 3, Figure 5 shows schematic plans for 16 different campsite areas at Baga Gazaryn Chuluu. In these cases much of the complexity of the campsite interior plans fades away and the ethnographic record begins to look more like the surface archaeological record (Figure 6). Keep in mind the patterns that were seen in the previous examples, such as flows of activities through the networks of the campsite and the existence of important, but archaeologically difficult to detect, activity areas (such as hitching and milking strings) within these campsites. At the level of detail of this set of examples we can see a clear pattern of orientation in which campsite structure begins with shelter from weather coming from the northwest. For this reason, dwellings and animal's shelters are built outward to the southeast. This form is used even when rock outcrops are not present and artificial shelter must be constructed (e.g., Figure 5b, d, h, and n). A clear system of relations of dwellings to the animals' corrals or resting areas is still visible. ${ }^{2}$ Paired gers are common, with the smaller serving as a kitchen, storage, or extra housing. The substantial amount of disturbed ground around the campsites is visible as tracks in snow on imagery but also through vegetation changes and changes in ground surface color and sediment composition. These indicate regular herd movements to and from graze and water. Areas of herd management close to camp as well as corrals and standing areas are connected to those pathways. In some cases (Figure $5 c, d, i$, and $\mathrm{m}$ ), a secondary standing area is visible in the patterns of disturbed ground.

Despite the lessening of detail, it is still possible to consider the overlapping areas of different household activities in these basic plans. Household space is again divided by the typical activities, dwellings, animal standing areas, shelter, paths, and so on. Work areas within camps are difficult to see at this scale, but if animal standing areas are divided into three polygons - one centered on the corral, one on the dwelling, and one focused on the central point of the standing area itself- - different 


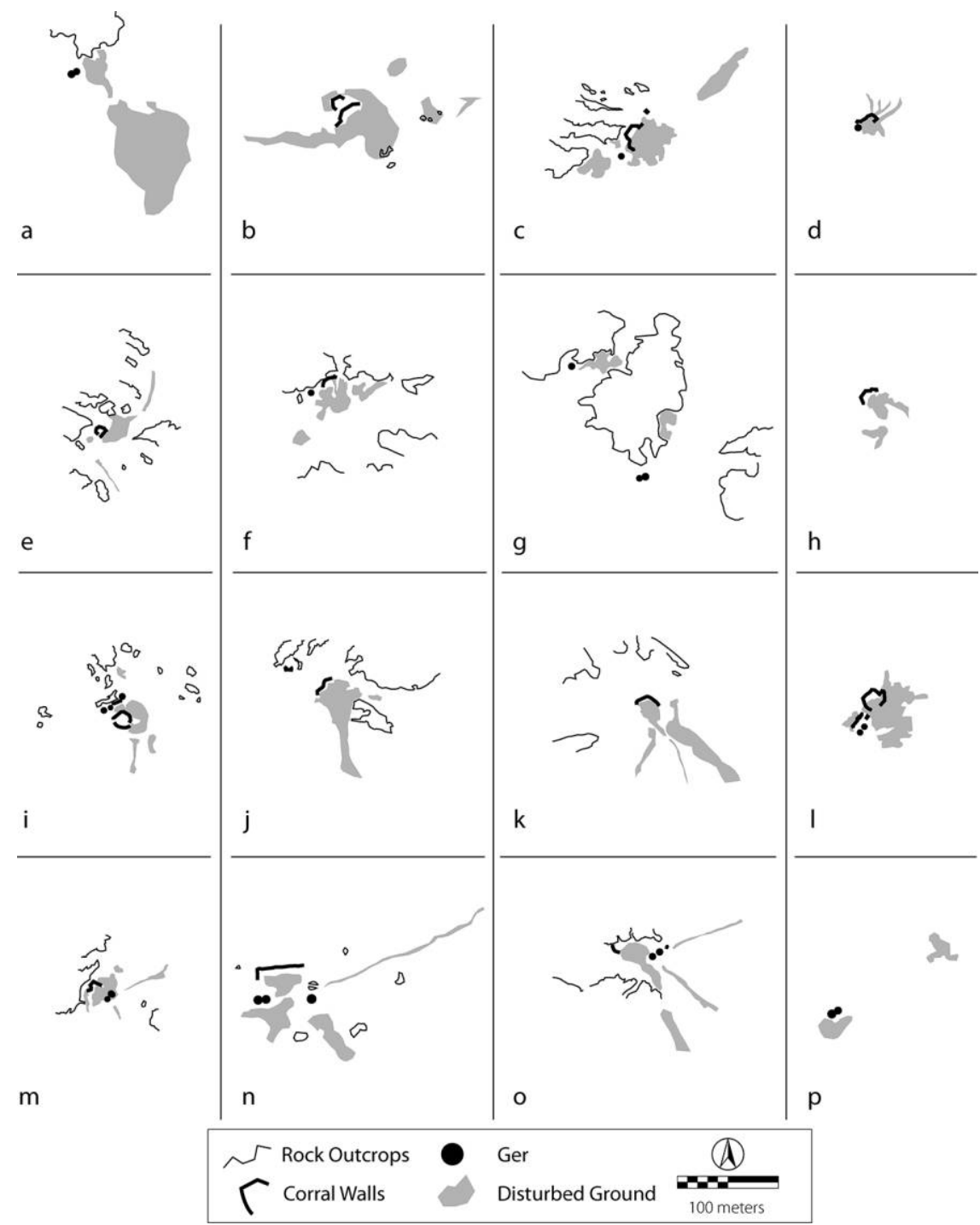

Figure 5. Plans of 16 inhabited areas at Baga Gazaryn Chuluu showing rock outcrops, corral walls, dwellings, pathways, and altered ground. Most are winter sites (a, g, and p are most likely summer sites). Drawings are rendered from aerial photos sourced from the Mongolian Institute of Geography through Monmap Engineering Services, based on Digital Globe imagery from Google Earth ${ }^{\text {TM }}$ Imagery and ground-level imagery made by the BGC project.

activity areas within the larger patch of disturbed ground can be suggested as well as the circulation of animals, herders, and milkers between these three areas divided between different genders and species. Another division is in camps with separate paths to water (Figure 5e, n, and o). One water path might be taken more frequently by 


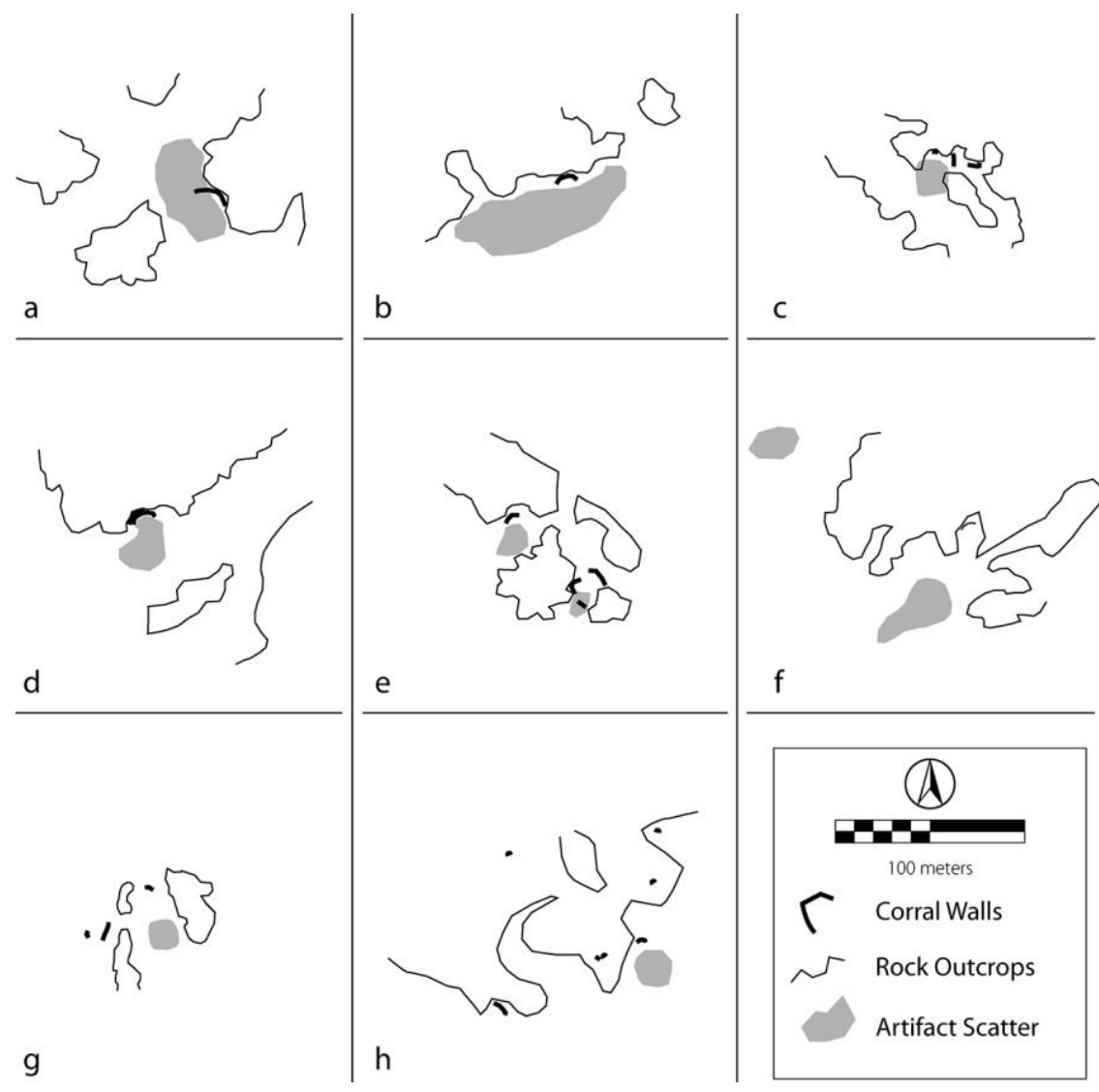

Figure 6. Plans of eight archaeological household sites at Baga Gazaryn Chuluu showing rock outcrops, stone alignments, and extent of artifact scatters. The key relationship is that between the artifact scatters and corral remains. Note the scale of the scatters relative to architectural features, the way that rock outcrops are used to supplement corrals, and the spaces around and between these two areas that could have formed activity areas or locations for portable dwellings. Also, corrals are movable structures. They are moved to new locations that offer similar shelter profiles. The many corral foundations in some of these plans show the long-term use history of a particular area.

women, children, and camels, while the other is used more frequently by men and sheep as they make the daily round from grazing grounds to camp.

By comparing the few summer sites shown here (Figure 5a, g, p) with the balance of the sites, which are mostly winter camps, patterns of different human and animal proximities can be seen. Humans and animals pack close to each other in the winter, are arranged to allow for visibility in spring or summer, and are separated by a distance in summer to decrease heat and flies. ${ }^{3}$ Finally, in both sets of 
modern campsite plans, traces of earlier ger outlines and corral rebuilding indicate that people return to the same areas. This increases the size of the archaeological signature of the household to more than 1 ha in most cases as well as diffusing it. Furthermore, erosion spreads altered soil and campsite debris downslope from the campsites. The erosion of corral fill is seen clearly in Figure 5a. This is an important quality of archaeological deposits.

\section{Archaeological Campsites at Baga Gazaryn Chuluu}

Schematic plans of eight archaeologically recorded campsites at BGC are presented in Figure 6. The sites feature corral traces and artifacts in close proximity. The BGC survey recorded 159 corrals, 13 with associated sherd scatters. Those not illustrated here were left out because of disturbance, mixed or unclear ceramic assemblages, or intermixing with other structures. The sherd scatters at most of these sites date to the late medieval period (ca. tenth through fourteenth centuries CE-the KhitanLiao or Mongol empires) with the exception of Figure 6e, which also featured later periods, and Figure 6c, with early medieval (sixth to ninth centuries CE-Türkic period) sherds. This site was also decorated with Türkic period rock art. Sites with corral traces were chosen because they provide a connection to the ethnographic examples given above in which at least three nodal points are apparent.

The patterns include the spreading of artifacts along low-energy soil erosion paths down into the bottoms of small valleys (visible in Figure 6a, b, and f). The off-center relationship of artifact scatters and corral remains is also clear. Two main causes for this might be the practice of placing trash deposits at the edge of the campsite or the incorporation of artifacts into animal standing areas and then the mixing of that midden of dung and artifacts with erosion surface flows. Finally, the archaeological campsites all show the importance of shelter to the north and northwest using natural outcrops or built corrals. In each of these cases, analogy and the relationship of shelter, corrals, and standing or disposal areas could be used to infer the possible locations of mobile dwellings and activity areas in archaeological sites. However, as a final note on these archaeological campsites, as we move farther into the past the study of household economic and social activities becomes the study of animals' activities. We have lost the surface archaeological traces of the human household completely. It is now via traces of the animals' lives, and where they overlapped with the lives of humans, that human households become visible in the archaeological record.

\section{DISCUSSION}

The model of the household presented here is focused on the spatial arrangement of the activities and infrastructure of everyday, regular, repeated interactions and tasks that sustain the household socially and economically. These points in space, and in time (Aldred 2013), are conceptualized as nodes in a network connected by regular movement. The fluid dwelling spaces of mobile pastoralists contain sets of elements 
in fixed relationships (kitchen-ger-hitching line, for example) that, when recreated, generate ordered arrangements in previously malleable space on the ground and in the world around it. These regular, repeated actions create domestic space, which is sustained over the long term with each setting up of a campsite and the recreation of familiar spaces and working systems in a new location. This also provides a regular reconstitution of relations with spaces around and outside the household by structuring the perception of the household's surroundings.

Mobile pastoralists' households are multi-species. They both create and are created by the relationships binding humans and animals into a single community (Fijn 2011). The study of the mobile pastoralist households of the Eurasian Steppe is a microcosm of the study of those same nomads and animals and their larger patterns of movement. Many choices, successes, and failures of a herding group happening at a household scale are the same as those happening on a regional scale. This is not to say that large-scale movements directly mimic the smaller movements of household activities or that one can effectively infer household structure from general knowledge about large-scale movement and subsistence patterns. Instead, cultural landscapes on multiple scales constitute one another.

The ancient mobile pastoralist households presented here are evidenced archaeologically by the relationship between corrals, disposal, and topography, the last of which provides shelter and results in erosion. The argument here is an analogical one (Wylie 1985), in which multiple connections are made between the remains of observable practices and archaeological remains to infer that those practices also took place in the past. I also suggest that less obtrusive things can be inferred in the past because of the long-standing, consistent relationships between different activity areas seen in the ethnographic record and only partially visible in the surface archaeological record. For example, we can see a disposal area or a dung pile, but we cannot see the kitchen or the corral that accompanied them, though we might assume that those activity areas would have been present. This highlights the fact that discussions here all make use of ethnographic observations and surface archaeological data recorded at the spatial and temporally coarse level of regional survey. Further fieldwork and excavation may test both inferences made here about the structure of households and also the antiquity of the regular networks that make up modern nomadic pastoralist households. This second question is one of the key foci of ongoing research on the antiquity of pastoralist practices in eastern Eurasia (Doumani et al. 2015; Guedes et al. 2013; Makarewicz 2015). Models of household structure offered here will guide future investigations of campsite sites that will integrate geophysics, soil chemistry, and microfauna with excavation. Of primary interest will be the antiquity of the particular triangular relationships between corrals and standing areas, dwellings, and work areas that have been highlighted in this study. The antiquity of the gender- and age-related household production activities visible ethnographically remains to be seen. However, the spatial approaches used here to organize the study of pastoralist households fit well with the long-established practice in archaeology 
of the recognition of gendered spaces in the built structures of households (Fliesher and Wynne-Jones 2012; Hastorf 1991; Sørensen 2013; Souvatzi 2012).

What does this current ethnographically dependent study offer to the archaeology of Mongolia and eastern Eurasia? The analysis presented here suggests a range of similarities between modern mobile pastoralist campsites in Mongolia and medieval campsites in the same region. These suggest a continuity of practice in herding and household arrangements over the past ca. 1300 years. The history of pastoral nomadism in the eastern steppe goes back at least 3000 years and probably more. What can we say about these earlier times in terms of campsites and household arrangements? The Xiongnu (fourth century $\mathrm{BC}$ to third century $\mathrm{AD}$ ) is one of the mostly intensively studied archaeological cultures in the Mongolian steppe (Brosseder and Miller 2011; Eregzen 2011; Honeychurch 2014), and large cemeteries of this period were found at BGC (Amartuvshin and Honeychurch 2010). These would have provided tangible anchors for nomadic Xiongnu people moving through the landscape, but what other evidence more directly related to household structure can we find for this period? Though there is evidence from isotopic data for the seasonal penning of sheep during the Xiongnu period at BGC (Makarewicz 2011, 2014, 2015), the archeological record there has not yet produced evidence of the corrals or pens themselves. Of the campsite areas depicted here only Figure 5g contained any Xiongnu period ceramics, and those were found on a valley mouth terrace close to a drainage channel. This is a locational pattern repeated by most of the 16 other sherd scatters of the Xiongnu period at BGC. The relative exposure to the wind and weather of these locations, along with comparison to modern sites (Figure 5a, g, and p, for example), suggest that in contrast to the medieval and Türkic period corral sites that form the bulk of the data presented in this paper, these sites might be nomadic summer habitations. The sherd deposits that define them may be the remains of disposal areas or erosion of surface middens into seasonal channels. This seasonal inference, contrasted with the isotopic evidence, suggests that the winter shelters of the Xiongnu herders of BGC have not yet been found.

The network-based model of household sites sets aside a need for built structures to define household activities and relies only on activity areas. Those areas are linked by common actors and multi-sited processes. Important nodes and regularly traveled links between them are the way in which a household is physically defined. This approach is flexible because the activities of the nodes and their relations are not predefined by the model, but by the particular contexts that are being examined. It is a tool equally useful in a village or city as in the steppe grassland. Also, this networked approach is extensible in that it has no borders and can expand to include a range of activities on a landscape as well as other households and their activities.

There is an elegant abstraction in the ephemeral archaeological traces of mobile pastoralist campsites — households without houses. They are for the most part made up of only a few sherds merged with impressions of their surroundings. These households are not directly represented through their structures and defined spaces but 
instead are reached through the filters of animal experiences and through the failed actors of a household network-broken vessels, animal skeletons, cracked milking stools, and the abandoned foundations of moveable stone corrals. Turning away from the specific place to their larger landscape context, these households are never in isolation. The needs of multiple species expand to fill the surrounding spaces and populate the landscape, fixing the household in its context through differing knowledge and perceptions of the landscape. The final element of the campsite's landscape is the ideal locale itself. For such a place, households of people and animals never move from their sheltered places_-only their constituents change as different families and herds inhabit a good place in the steppe.

\section{NOTES}

The research that provided the basis for this paper was carried out in collaboration with the Institutes of History and Archaeology of the Mongolian Academy of Sciences and would not have been possible without my colleagues Chunag Amartuvshin, William Honeychurch, and D. Molor and the hospitality of the people of Egiin Gol and Baga Gazaryn Chuluu. The work was supported by the Center for the Study of Eurasian Nomads, the Wenner-Gren Foundation, the National Geographic Society, the Institute of Archaeology of the Mongolian Academy of Sciences, the National Science Foundation, Gettysburg College, Yale University, the Smithsonian Museum's National Museum of Natural History, the Department of Anthropology at Harvard University, the American School for Prehistoric Research, and the Gerda Henkel Stiftung.

1. The stone walls that form the lower sections of winter animal shelters throughout much of Mongolia are not as enduring as they might seem. Informants in Baga Gazaryn Chuluu — a place with many many rocks_-describe moving the stones of their family's winter barn walls to new places.

2. This southwest-northeast linear relationship is not universal at BGC. A few other examples of alternative arrangements are not depicted here because of the poor quality of the imagery currently available.

3. Flies are an annoyance for people and animals. In Figure 3 a burnt area can be seen on the ground near the corral and kitchen. This is the residue of a smudge pile of smoldering dung built to discourage flies. These are found at almost every fall and summer campsite in the Egiin Gol valley. In the Gobi region, dung fuel is saved for the winter and animals are penned farther away from human dwellings and work areas.

\section{REFERENCES CITED}

Adey, Peter. 2006. If mobility is everything, then it is nothing: Towards a relational politics of (im)mobilities. Mobilities 1(1):75-94.

Aldred, Oscar. 2013. "Farmers, sorting folds, earmarks, and sheep in Iceland," in Archaeologies of mobility and movement. Edited by M. C. Beaudry and T. G. Parno, pp. 47-63. New York: Springer. 
Amartuvshin, Ch., and W. Honeychurch, eds. 2010. Dundgobi aimagt hiisen arkheologiin sudalgaa: Baga gazaryn chuluu [Archaeological research in the Middle Gobi: Baga Gazaryn Chuluu]. Ulaanbaatar: Mongolian Academy of Science, Institute of Archaeology.

Ames, Kenneth M., Doria F. Raetz, Stephen Hamilton, and Christine McAfee. 1992. Household archaeology of a southern Northwest Coast plank house. Journal of Field Archaeology 19(3):275-90.

Anthony, David W. 2007. The horse, the wheel, and language. Princeton: Princeton University Press.

Anthony, David W., and Dorcas Brown. 2007. "The herding-and-gathering economy at Krasnosamarskoe, Russia, and the end of the dependency model of steppe pastoralism," in Social orders and social landscapes. Edited by L. Popova, C. Hartley, and A. Smith, pp. 393-415. Newcastle: Cambridge Scholars.

Beck, Lois. 1991. Nomad: A year in the life of a Qashqa'i tribesman in Iran. Berkeley: University of California Press.

Becker, H., and J. W. E. Fassbinder. 1999. "Magnetometry of a Scythian settlement in Siberia near Cicah in the Baraba Steppe," in Archaeological prospection: Third International Conference on Archaeological Prospection. Edited by J. W. Fassbinder and W. E. Irlinger, pp. 168-72. Munich: Bayerisches Landesamt für Denkmalpflege.

Bender, Barbara, Sue Hamilton, and Chris Tilley. 2007. Stone worlds: Narrative and reflexivity in landscape archaeology. Walnut Creek, CA: Left Coast Press.

Binford, Lewis R. 1978. Nunamiut ethnoarchaeology. New York: Academic Press.

. 1980. Willow smoke and dogs' tails: Hunter-gatherer settlement systems and archaeological site formation. American Antiquity 45:4-20.

Brosseder, Ursula, and Bryan K. Miller, eds. 2011. Xiongnu archaeology: Multidisciplinary persepectives of the first steppe empire in Inner Asia. Bonn Contributions to Asian Archaeology 5. Bonn: Vor- und Frühgeschichtliche Archäologie Rheinische Friedrich-WilhelmsUniversität.

Burger, Oskar, Lawrence C. Todd, Paul Burnett, Tomas J. Stohlgren, and Doug Stephens. 2004. Multi-scale and nested-intensity sampling techniques for archaeological survey. Lournal of Field Archaeoloogy 29(3/4):409-23.

Büscher, Monika, and John Urry. 2009. Mobile methods and the empirical. European Iournal of Social Theory 12(1):99-116.

Cavanagh, William, Christopher Mee, Peter James, Neil Brodie, and Tristan Carter. 2005. The Laconia Rural Sites Project, supplementary volumes. London: The British School at Athens.

Chang, Claudia, and Harold A. Koster. 1986. Beyond bones: Toward an archaeology of pastoralism. Advances in Archaeological Method and Theory 9:97-148.

Cribb, Roger. 1991a. Nomads in archaeology. Cambridge: Cambridge University Press.

_ 1991b. "Mobile villagers: The structure and organization of nomadic pastoral campsites in the Near East," in Ethnoarchaeological approaches to mobile campsites. Edited by C. S. Gamble and W. A. Boismier, pp. 371-93. Ann Arbor: International Monographs in Prehistory.

Danilov, Sergei V. 2011. "Typology of ancient settlement complexes of the Xiongnu in Mongolia and Transbaikalia," in Xiongnu archaeology: Multidisciplinary persepectives of the first steppe empire in Inner Asia. Edited by U. Brosseder and B. K. Miller, pp. 129-36. Bonn: Vor- und Frühgeschichtliche Archäologie, Rheinische Friedrich-Wilhelms-Universität. 
Davydova, A.V. 1968. The Ivolga Gorodishche (A monument of the Hiung-Nu culture in the Trans-Baikal region). Acta Archaeologica Academiae Scientiarium Hungaricae 20:209-45. 1995. Ivolginskoe gorodishche [The Ivolga fortress]. Archaeological Monuments of the Xiongnu, vol. 1. Saint Petersburg: Asiatic Fund.

de Haas, Tymon. 2012. "Beyond dots on the map: Intensive survey data and the interpretation of small sites and off-site distributions," in Comparative issues in the archaeology of the Roman rural landscape: Site classification between survey, excavation and historical categories. Edited by P. Attema and G. Schörner, pp. 55-79. Journal of Roman Archaeology Supplement 88.

de Laet, Marianne, and Annemarie Mol. 2000. The Zimbabwe bush pump: Mechanics of a fluid technology. Social Studies of Science 30(2):225-63.

Doumani, Paula N., Michael D. Frachetti, Rebecca Beardmore, Tekla M. Schmaus, Robert N. Spengler III, and Alexei N. Mar'yashev. 2015. Burial ritual, agriculture, and craft production among Bronze Age pastoralists at Tasbas (Kazakhstan). Archaeological Research in Asia 1(1):17-32.

Ekvall, Robert B. 1968. Fields on the hoof: Nexus of Tibetan nomadic pastoralism. New York: Holt, Rinehard, and Winston.

Erdenebaatar, B. 1996. "Socio-economic aspects of the pastoral movement: Patterns of Mongolian herders," in Culture and environment in Inner Asia. Edited by C. Humphrey and D. Sneath, pp. 58-110. Cambridge: White Horse Press.

Eregzen, G., ed. 2011. Хүннүгийн өв [Treasures of the Xiongnu]. Ulaanbaatar: ShUA-iin Arkheologiin khureelen, Mongolyn Undesnii muzei.

Fernandez-Gimenez, Maria E. 2006. "Land use and land tenure in Mongolia: A brief history and current issues," in Rangelands of Central Asia: Proceedings of the Conference on Transformations, Issues, and Future Challenges. Edited by D. J. Bedunah, E. D. McArthur, and M. Fernandez-Gimenez, pp. 30-36. Ft. Collins, CO: U.S. Department of Agriculture, Forest Service, Rocky Mountain Research Station Proceeding RMRS-P-39.

Fijn, Natasha. 2011. Living with herds: Human-animal coexistence in Mongolia. Cambridge: Cambridge University Press.

Fish, Suzanne K., and Stephen A. Kowalewski, eds. 1990. The archaeology of regions: A case for full-coverage survey. Washington, DC: Smithsonian Institution Press.

Fisher, John W. Jr., and Helen C. Strickland. 1989. Ethnoarchaeology among the Efe pygmies, Zaire: Spatial organization of campsites. American Journal of Physical Anthropoloog 78(4):473-84.

Fleisher, Jeffrey, and Stephanie Wynne-Jones. 2012. Finding meaning in ancient Swahili spatial practices. African Archaeolooical Review 29(2-3):171-207.

Glowacki, Kevin T., and Natalia Vogeikoff-Brogan, eds. 2011. ГTEГA: The archaeology of houses and households in ancient Crete, Hesperia supplements. Princeton: American School of Classical Studies at Athens.

Gorynova, O. I. 1983. "Bronze Age complex at the multilayer settlement of Tishikine III," in Research on the ancient cultures of Cisbaikal. Edited by P. B. Konavalov, pp. 70-75. Novosibirsk.

Guedes, Jade d'Alpoim, Hongliang Lu, Yongxian Li, Robert N. Spengler, Xiaohong Wu, and Mark S. Aldenderfer. 2013. Moving agriculture onto the Tibetan plateau: The archaeobotanical evidence. Archaeolooical and Anthropological Sciences 6(3):255-69. 
Hämäläinen, Pekka. 2003. The rise and fall of Plains Indian horse cultures. Lournal of American History 90:833-62.

Hammer, Emily. 2014. Local landscape organization of mobile pastoralists in southeastern Turkey. Journal of Anthropological Archaeolooy 35:269-88.

Hanks, Bryan. 2010. Archaeology of the Eurasian Steppes and Mongolia. Annual Review of Anthropolooy 39:469-86.

Hastorf, Christine. 1991. "Gender, space, and food in prehistory," in Engendering archaeology: Women in prehistory. Edited by J. Gero and M. Conkey, pp. 132-59. Oxford: Basil Blackwell.

Head, Lesley, and Richard Fullagar. 1997. Hunter-gatherer archaeology and pastoral contact: Perspectives from the northwest Northern Territory, Australia. World Archaeology 28(3):418-28.

Hendon, Julia A. 2008. "Living and working at home: The social archaeology of household production and social relations," in Companion to social archaeology. Edited by L. Meskell and R. Preucel, pp. 272-86. Malden, MA: Blackwell.

Hill, Kim R., Robert S. Walker, Miran Božičević, James Eder, Thomas Headland, Barry Hewlett, A. Magdalena Hurtado, Frank Marlowe, Polly Wiessner, and Brian Wood. 2011. Co-residence patterns in hunter-gatherer societies show unique human social structure. Science 331:1286-89.

Ho, Engseng. 2006. The graves of Tarim: Geneology and mobility across the Indian Ocean. Berkeley: University of California Press.

Hodgetts, Lisa M. 2007. The changing pre-Dorset landscape of SW Hudson Bay, Canada. Lournal of Field Archaeoloogy 32:353-67.

Honeychurch, William. 2014. Alternative complexities: The archaeology of pastoral nomadic states. Iournal of Archaeolooical Research 22(4):277-326.

Honeychurch, William, and Amartuvshin Chunag. 2007. Hinterlands, urban centers, and mobile settings: The "new" Old World archaeology from the Eurasian Steppe. Asian Perspectives 46 (1):36-64.

Honeychurch, William, Joshua Wright, and Chunag Amartuvshin. 2007. A nested approach to survey in the Egiin Gol Valley, Mongolia. Lournal of Field Archaeology 32:339-52.

Houle, Jean-Luc, and Diimaazhav Erdenebaatar. 2009. "Investigating mobility, territoriality and complexity in the Late Bronze Age: An initial perspective from monuments and settlements," in Current archaeological research in Mongolia. Edited by J. Bemmann, H. Parzinger, E. Pohl, and D. Tseveendorzh, pp. 117-48. Bonn Contributions to Asian Archaeology 4. Bonn: Vor- und Frühgeschichtliche Archäologie, Rheinische FriedrichWilhelms-Universität.

Humphrey, Caroline. 1974. "Inside a Mongolian tent." New Society (October 31). Available online at http://innerasiaresearch.org/CHsite/pdfs/Humphrey.\%201974.\%20In\%20 a\%20Mongolian\%20tent.pdf

Humphrey-Waddington, Caroline. 1974. Horse brands of the Mongolians: A system of signs in a nomadic culture. American Ethnologist 1(3):471-88.

Iakovleva, L., F. Djindjian, E. N. Maschenko, S. Konik, and A-M. Moigne. 2012. The Late Upper Palaeolithic site of Gontsy (Ukraine): A reference for the reconstruction of the hunter-gatherer system based on a mammoth economy. Quaternary International 255:86-93. 
Ingold, Tim. 1993. The temporality of landscape. World Archaeology 25(2):153-74. 2000. The perception of the environment: Essays on livelihood, dwellino and skill. New York: Routledge.

Jacobs, Andrew. 2010. Winter leaves Mongolians a harvest of carcasses. New York Times (May 19). http://www.nytimes.com/2010/05/20/world/asia/20mongolia.html?scp=11\&sq $=$ Mongolia\&st $=$ nyt.

Jacobson-Tepfer, Esther, James E. Meacham, and Gary Tepfer. 2010. Archaeology and landscape in the Mongolian Altai: An atlas. Redlands, CA: ESRI Press.

Jagchid, S., and P. Hyer. 1979. Mongolia's culture and society. Boulder: Westview.

Joly, Frédéric J. C., Tulganyam Samdanjigmed, Valérie Cottereau, and Claudia Feh. 2013. Ecological constraints on and consequences of land use heterogeneity: A case study of the Mongolian Gobi. Lournal of Arid Environments 95:84-91.

Kakinuma, Kaoru, Takahiro Ozaki, Seiki Takatsuki, and Jonjin Chuluun. 2008. How pastoralists in Mongolia perceive vegetation changes caused by grazing. Nomadic Peoples 12 (2): 67-73.

Kato, Shimpei, and Noriyuki Shiraishi, eds. 2005. Avraga I. Occasional Paper on the Excavations of the Palace of Genghis Khan. New Directions in Mongolian Archaeology, vol. 1. Niigata: Department of Archaeology, Faculty of Humanities, Niigata University.

Kelly, Robert L. 1992. Mobility/Sedentism: Concepts, archaeological measures and effects. Annual Review of Anthropolooy 21:43-66.

Kowalewski, Stephen A. 2008. Regional settlement pattern studies. Lournal of Archaeolooical Research 16:225-85.

Kradin, Nikolay N., and Alexander L. Ivliev. 2008. Deported nation: The fate of the Bohai people of Mongolia. Antiquity 82:438-45.

Larichev, Vitalii Epifanovich, and Barbara L. Pforr. 1962. Neolithic settlements in CisBaikal (1957-1959 excavations). Arctic Anthropology 1(1):93-95.

Latour, Bruno. 2005. Reassembling the social. Oxford: Oxford University Press.

Lattimore, Owen. 1979. "Herdsmen, farmers, urban culture," in Pastoral production and society. Edited by C. Lefebvre, pp. 479-90. Cambridge: Cambridge University Press and the Centre National de la Recherche Scientifique.

Law, John. 2009. "Actor network theory and material semiotics," in The new Blackwell companion to social theory. Edited by B. S. Turner, pp. 141-58. Oxford: Blackwell.

Lefebvre, Henri. 1991. The production of space, trans. by Donald Nicholson-Smith. Oxford: Blackwell.

Luby, E. M, C. D. Drescher, and K. G. Lightfoot. 2006. Shell mounds and mounded landscapes in the San Francisco Bay area: An integrated approach. Lournal of Island and Coastal Archaeoloogy 1(2):191-214.

Makarewicz, Cheryl. 2011. "Xiongnu pastoral systems: Integrating economies of subsistence and scale," in Xiongnu archaeology: Multidisciplinary perspective on the first steppe empire in Central Asia. Edited by U. Brosseder and B. K. Miller, pp. 181-92. Bonn: Vor- und Frühgeschichtliche Archäologie, Rheinische Friedrich-Wilhelms-Universität.

2014. Winter pasturing practices and variable fodder provisioning detected in nitrogen $(\mathrm{d} 15 \mathrm{~N})$ and carbon (d13C) isotopes in sheep dentinal collagen. Lournal of Archaeolooical Science 41:502-10. 
2015. Winter is coming: Seasonality of ancient pastoral nomadic practices revealed in the carbon $\left(\delta^{13} \mathrm{C}\right)$ and nitrogen $\left(\delta^{15} \mathrm{~N}\right)$ isotopic record of Xiongnu caprines. Archaeological and Anthropological Sciences. Doi: 10.1007/s12520-015-0289-5

Makarewicz, Cheryl, and Noreen Tuross. 2006. Foddering by Mongolian pastoralists is recorded in the stable $(\mathrm{d} 13 \mathrm{C})$ and nitrogen $(\mathrm{d} 15 \mathrm{~N})$ isotopes of caprine dentinal collagen. Lournal of Archaeolooical Science 33(6):862-70.

Mearns, Robin. 1993. Territoriality and land tenure among Mongolian pastoralists: Variation, continuity and change. Nomadic Peoples 33:73-103.

Mitchell, Peter, Ina Plug, Geoff Bailey, Ruth Charles, Amanda Esterhuysen, Julia Lee Thorp, Adrian Parker, and Stephan Woodborne. 2011. Beyond the drip-line: A high-resolution open-air Holocene hunter-gatherer sequence from highland Lesotho. Antiquity 85:122542 .

Mithen, Steven, ed. 2000. Hunter-gatherer landscape archaeology: The southern Hebrides Mesolithic project. Cambridge: Macdonald Institute.

Murphy, Daniel J. 2012. "Encountering the franchise state: Dzud, Otor, and transformations in pastoral risk," in Mongolia after socialism. Edited by B. Knauft, pp. 68-80. Ulaanbaatar: Admon.

Newman, Mark. 2010. Networks: An introduction. Oxford: Oxford University Press.

Pedersen, Morten A. 2006. "Where is the centre? The spatial embeddedness of power in post-socialist rural Mongolia," in Mongolia from country to city. Edited by O. Bruun and L. Narangoa, pp. 82-109. Copenhagen: Nordic Institute of Asian Studies.

2009. "At home away from homes: Navigating the taiga in northern Mongolia," in Boundless worlds: An anthropological approach to movement. Edited by P. W. Kirby, pp. 135-51. New York: Berghahn Books.

Perlee, Kh. 1962. "Kidan'skie Goroda i Poseleniia na Territorii Mongol'skoi Narodnoi Respubliki (X - nachalo XII v.)," in Mongol'skii Arkhaeologicheskii Sobrnik. Edited by S.V. Kiselev, pp. 55-62. Moscow.

Piggott, Stuart. 1944. Nomad house-sites in the western Himalayas. Man 44:150-52.

Plog, Stephen, Fred Plog, and Walter Wait. 1978. Decision making in modern surveys. Advances in Archaeological Method and Theory 1:383-421.

Potts, D. T. 2014. Nomadism in Iran: From antiquity to the modern era. Oxford: Oxford University Press.

Ramseyer, D., and Ts. Turbat. 2007. The settlement of Boroo Gol (Selenge): A village of the Xiongnu Period. Paper presented at the Archaeological Research in Mongolia, 1st International Conference, August 19-23, Ulaanbaatar, Mongolia.

Rautio, Anna-Maria, Torbjörn Josefsson, and Lars Östlund. 2014. Sami resource utilization and site selection: Historical harvesting of inner bark in northern Sweden. Human Ecology 42:137-46.

Shahack-Gross, Ruth, Fiona Marshall, Kathleen Ryan, and Steve Weiner. 2004. Reconstruction of spatial organization in abandoned Maasai settlements: Implications for site structure in the pastoral Neolithic of East Africa. Journal of Archaeological Science 31:1395-1411.

Simukov, A.D. 2007 [1934]. Труды о Монголии и для Монголии [Works about Mongolia and for Mongolia]. Senri Ethnological Reports. Osaka: National Museum of Ethnology. 
Spengler, Robert N., Michael D. Frachetti, and Gayle J. Fritz. 2013. Ecotopes and herd foraging practices in the steppe/mountain ecotone of Central Asia during the Bronze and Iron Ages. Lournal of Ethnobiology 33(1):125-47.

Sørensen, M. L. S. 2013. Gender archaeology. New York: Wiley.

Souvatzi, Stella. 2012. "Space, place, and architecture: A major meeting point between social archaeology and anthropology?" in Archaeology and anthropology: Past, present and future. Edited by D. Shankland, pp. 173-96. London: Berg.

Sundstrom, Linea. 1993. A simple mathematical procedure for estimating the adequacy of site survey strategies. Iournal of Field Archaeoloogy 20(1):91-96.

Torbat, Ts., Ch. Amartuvshin, and U. Erdenbat. 2003. Эгийн Гольн Сав Нутаг Дахь Археологийн Дурсгалууд [Archaeological monuments of Egiin Gol Valley]. Ulaan Bataar: Mongolian Academy of Science, Institute of Archaeology.

Umekazu, Kawagishi, Sugimoto Hirofumi, Kitano Koki, Gonchigbat Ishjamts, and Hirota Naoyuki. 2010. Living environment of nomads residing on the outskirts of Ulaanbaatar, Mongolia, Part 2: Lifestyle and living environment from the perspective of perceptions and activities. Iournal of Asian Architecture and Buildino Enoineering 9(1):139-46.

Urry, John. 2000. Mobile sociology. British Journal of Sociology 51(1):185-203.

Vainshtein, Sevyan. 1980. Nomads of South Siberia: The pastoral economies of Tuva. Cambridge: Cambridge University Press.

Weber, Andrzej W., and Robert Bettinger. 2010. Middle Holocene hunter-gatherers of CisBaikal, Siberia: An overview for the new century. Iournal of Anthropolooical Archaeoloory 29(4):491-506.

Whitelaw, Todd. 1983. People and space in hunter-gatherer camps: A generalizing approach to ethnoarchaeology. Archaeological Review from Cambridge 2(2):48-66.

Wilk, Richard R., and William L. Rathje. 1982. Household archaeology. American Behavioral Scientist 25(6):617-39.

Wilkinson, T. J. 2003. Archaeological landscapes of the Near East. Tucson: University of Arizona Press.

Williams, James T. 2008. The Tahilt region: A preliminary archaeological survey of the Tahilt surroundings to contextualize the Tahilt cemeteries. The Silk Road 5(2):42-47.

Wood, Brian M., and Frank W. Marlow. 2014. Toward a reality-based understanding of Hadza men's work. Human Nature 25(4):620-30.

Wright, Joshua. 2007. Organization principles of Khirigsuur monuments in the Lower Egiin Gol Valley, Mongolia. Lournal of Anthropolooical Archaeology 26:350-65.

2010. "Methods of archaeological survey," in Dundgobi aimagt hiisen arkheologiin sudalgaa: Baga Gazaryn Chuluu [Archaeological Research in the Middle Gobi: Baga Gazaryn Chuluu], edited by Ch. Amartuvshin and W. Honeychurch. Ulaanbaatar: Mongolian Academy of Science, Institute of Archaeology.

— 2012. "Temporal perspectives on the monumental constellations of Inner Asia," in "As time goes by?" Monumentality, landscapes and the temporal perspective. Edited by M. Furholt, M. Hinz, and D. Mischka, pp. 73-83. Bonn: Verlag Dr. Rudolf Habelt. 2014. Landscapes of inequality? A critique of monumental hierarchy in the Mongolian Bronze Age. Asian Perspectives 51(2):139-63.

Wright, Joshua, William Honeychurch, and Chunag Amartuvshin. 2007. Initial findings of the Baga Gazaryn Chuluu archaeological survey (2003-2006). Antiquity 81(313): Project Gallery. 
2009. The Xiongnu settlements of Egiin Gol, Mongolia. Antiquity 83(320):372-87. . n.d. Continuity and authority in the Mongolian steppe: The Egiin Gol survey 19972002. New Haven: Yale University Publications in Anthropology (in press).

Wylie, Alison. 1985. "The reaction against analogy," in Advances in archaeological method and theory. Edited by Michael J. Schiffer, pp. 63-111. New York: Academic Press.

Xie, Yina, and Wenjun Li. 2008. Why do herders insist on otor? Maintaining mobility in Inner Mongolia. Nomadic Peoples 12(2):35-52.

Yates, Timothy. 1989. "Habitus and social space: Some suggestions about meaning in Saami (Lapp) tents, ca. 1700-1900," in The meanings of things: Material culture and symbolic expression. Edited by Ian Hodder, pp. 249-62. London: Unwin Hyman.

Zemmrich, A., M. Manthey, S. Zerbe, and D. Oyunchimeg. 2010. Driving environmental factors and the role of grazing in grassland communities: A comparative study along an altitudinal gradient in western Mongolia. Iournal of Arid Environments 74:1271-80. 